\title{
Effect of Coagulant Dosage on Tofu Industry Wastewater Treatment in Combination with Ultrafiltration Process using Polysulfone Membrane
}

\author{
Aditha Oktariany ${ }^{1}$ and Sutrasno Kartohardjono, ${ }^{1, *}$ \\ ${ }^{1}$ Intensification Process Laboratory, Department of Chemical Engineering Universitas Indonesia, Kampus UI Depok 16424, Indonesia.
}

\begin{abstract}
Wastewater from tofu industry is one of water pollution sources that still require more effective treatment. This study aim to treat wastewater from tofu industry through a combination of coagulation-flocculation and ultrafiltration processes. Coagulation-flocculation is conducted prior to ultrafiltration process to minimize the effect of fouling on membrane and to improve the performance of ultrafiltration process. Poly aluminum chloride (PAC) was used as coagulant with doses of 100, 200, 300, 400 and $500 \mathrm{ppm}$. The wastewater feed have $\mathrm{pH}$, total dissolved solid (TDS), total suspended solids (TSS), turbidity and chemical oxygen demand in the ranges of 3.8 4, 850 - $880 \mathrm{mg} / \mathrm{L}, 380$ - $420 \mathrm{mg} / \mathrm{L}, 450-530 \mathrm{FAU}$ and 5600 - $6600 \mathrm{mg} / \mathrm{L}$, respectively. Experimental results showed that the effectiveness of coagulation increased with the addition of coagulant dose until the optimum dose is reached. After coagulation-flocculation process, COD, TSS, and turbidity decreased, whereas TDS increased. The optimum dose of the coagulationflocculation process was then used for a combination of coagulation-flocculation and ultrafiltration processes. The result of this combination process showed a decrease in COD, BOD, TSS, and turbidity.
\end{abstract}

\section{Introduction}

Indonesia is a country that has a large consumption of soybeans. The average per capita consumption per week of Indonesian people per year 2015 reaches $0.144 \mathrm{~kg}$ [1]. In 2012 , the total national need for soybeans reaches 2.2 tons, with the largest percentage allocation of this amount absorbed by the tofu and soybean cake food industries that is $83.7 \%$ [2]. This large demand is then followed by large number of tofu industries in Indonesia, where the number of medium and large business enterprises of tofu manufacture from soybeans per year in 2013 reaches 141 with a trend of increase of $1.41 \%$ annually [3], but the amount is dominated by small industries which is found in almost all regions in Indonesia.

The increase in the number of industries and tofu production is also followed by the amount of wastewater produced. Wastewater production from tofu industries reaches 20 million $\mathrm{m}^{3} /$ year, where for every $100 \mathrm{~kg}$ of soybeans, 1.5 to $2 \mathrm{~m}^{3}$ of water is required. The wastewater of tofu has high organic content i.e. BOD (Biological Oxygen Demand) value about 6000 - 8000 $\mathrm{mg} / \mathrm{L}$ and COD (Chemical Oxygen Demand) about $7,500-26,000 \mathrm{mg} / \mathrm{L}[4,5]$. Meanwhile, according to the Ministry of Environment, the quality standard of waste from soybean processing industry should have BOD value of $150 \mathrm{mg} / \mathrm{L}, \mathrm{COD}$ of $275 \mathrm{mg} / \mathrm{L}$, and TSS (Total Suspended Solids) of $100 \mathrm{mg} / \mathrm{L}$ with a $\mathrm{pH}$ of about 6-9 $[6,7]$. Some researcher have conducted studies to utilize wastewater from tofu industry such as for denitrification of tail water [8], hydrogen production [9], a medium for microalgae culture [10] and bioethanol production [11]. The wastewater from tofu industry is mostly thrown away into the river, which can endanger river biota, cause unpleasant odors, and pollute groundwater sources especially for people around tofu industry. Some health problems that can be caused of skin diseases, digestive problems and some other health problems.

To date, the wastewater treatment methods applied in tofu industries are mostly use the help of microorganisms. In addition to the ineffectiveness, the processing time required was relatively long, reaching 4 weeks. A processing method that has higher effectiveness with a shorter processing time is required to process this wastewater, given the large amount of production every day. One method that is considered effective for treating a liquid waste with high protein and fat emulsion content is by using ultrafiltration membrane technology [12] with pre-treatment in the form of coagulation-flocculation method. This study aims to evaluate the performance and effectiveness of combinations of coagulation-flocculation and ultrafiltration processes in reducing TSS, TDS, COD, BOD, dissolved oxygen (DO) and turbidity levels of wastewater from tofu industry.

\section{Materials and Methods}

Corresponding author: sutrasno@che.ui.ac.id 
The wastewater used in the experiment was taken from tofu factory in Lenteng Agung South Jakarta. The $p \mathrm{H}$ of wastewater was adjusted to around 7 by adding appropriate volume of $2.0 \mathrm{M} \mathrm{NaOH}$ solutions prior to flocculation-coagulation process. The coagulant was prepared by dissolving 5 gram of PAC into $200 \mathrm{ml}$ of distilled water. The solution for flocculation-coagulation process was prepared by adding $1 \mathrm{ml}$ coagulant solution into a beaker glass containing $250 \mathrm{ml}$ of wastewater solution. The flocculation-coagulation processes were conducted in Jar Test VELP JLT-6 at $120 \mathrm{rpm}$ for 2 minutes and then $40 \mathrm{rpm}$ for 10 minutes. The solution from the flocculation-coagulation processes were placed for 30 minutes and then were filtered using BIPMED BI filter paper sized $10 \mu \mathrm{m}$. The filtrate was used as a feed solution into ultrafiltration (UF) process. The UF membrane used was polysulfone hollow fiber module provided by CV GDP Filter Bandung Indonesia. The pressurized air was used to create the Trans membrane pressure during the ultrafiltration process. The observed parameters such as TSS, TDS, COD, dissolved oxygen (DO) and turbidity were measured for the wastewater before and after the flocculation-coagulation processes and after the ultrafiltration process, while BOD is only measured after the ultrafiltration process. TSS, DO and turbidity were measured using Colorimeter DR/890, DO was measured using Hanna combo $\mathrm{pH}$ and EC and COD was measured using Spectrophotometer UV-Vis BEL UV-MS1 single beam. The schematic diagram of the experiment is presented in Fig. 1.

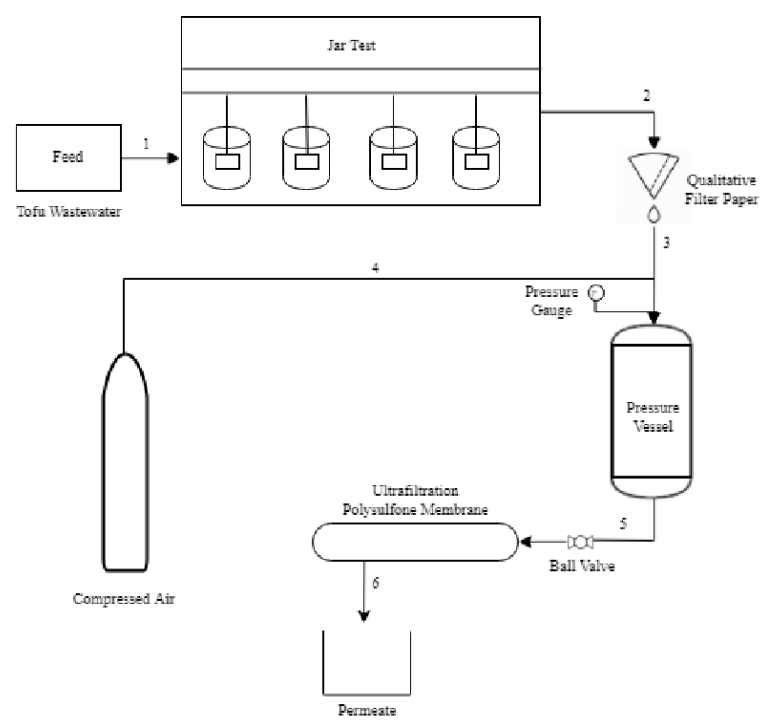

Fig. 1. Schematic diagram of experimental set up.

\section{Results and Discussion}

The characteristics of tofu wastewater used in the experiments are presented in Table 1. It can be seen that the tofu wastewater has parameter values deviating from environmental quality standard based on Ministry of Environment Regulation no. 5 Year 2014 [6], so that it should not be directly discharged into the environment. The tofu wastewater has an acidic $p \mathrm{H}$ of less than 4 so it can be corrosive. It also has a large suspended solid as indicated by the high amount of TSS, COD and turbidity. In addition, the tofu wastewater causes odor and rot when it left for 24 hours due to organic substances in the wastewater, which is susceptible to decay when there is contact with oxygen as indicated by high BOD parameter.

Table 1. The characteristics of the tofu wastewater used in the study.

\begin{tabular}{|l|c|c|}
\hline $\begin{array}{c}\text { Observed } \\
\text { Parameters }\end{array}$ & $\begin{array}{c}\text { Concentration } \\
\text { range }\end{array}$ & $\begin{array}{c}\text { Government } \\
\text { Regulation [6] }\end{array}$ \\
\hline$p \mathrm{H}$ & 3.8 & $6.0-9.0$ \\
\hline TDS $(\mathrm{mg} / \mathrm{L})$ & $870-1080$ & 2000 \\
\hline TSS $(\mathrm{mg} / \mathrm{L})$ & $381-414$ & 100 \\
\hline Turbidity (FAU) & $397-484$ & 25 \\
\hline COD $(\mathrm{mg} / \mathrm{L})$ & $5981-6525$ & 275 \\
\hline BOD $(\mathrm{mg} / \mathrm{L})$ & 2900 & 150 \\
\hline
\end{tabular}

Figure 2 shows the effect of PAC dosage on the effectiveness of the coagulation-flocculation process on TSS. TSS decreased in the coagulation-flocculation process due to the addition of $\mathrm{NaOH}$ to adjust the $p \mathrm{H}$ of wastewater to 7 . The $p \mathrm{H}$ applied is related to the effectiveness of the coagulation process, where at the $p \mathrm{H}$ of about 6-7 PAC has a lower solubility than other $\mathrm{pH}$ so that the coagulant is maximally converted to the flock [13]. TSS from tofu wastewater experienced reduction to almost $50 \%$ after coagulation-flocculation. This phenomenon is in accordance with the existing theory, where when the coagulation process-flocculation running at the optimum $p \mathrm{H}$ and fast stirring time and appropriate slow stirring, it will destabilize the suspended solid so that the coagulation process run effectively. A large flock formed after slow stirring was precipitated at sufficient time i.e. 30 minutes. After precipitation, these large flocks accumulated and settled at the bottom resulting in fine white grains which were then filtered and separated from the processed tofu wastewater solution. Once filtered, solids sized greater than 10 microns are no longer present in tofu wastewater solution. It can be seen from Figure 2 that a coagulant dose of PAC 300-500 ppm gives relatively constant degradation, so that a dose of $300 \mathrm{ppm}$ will be used for ultrafiltration process.

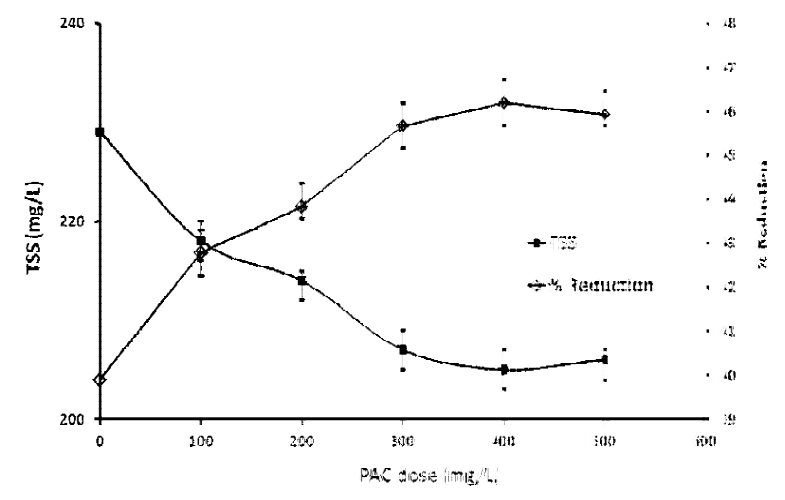

Fig. 2. TSS and TSS reduction of wastewater after coagulationflocculation process as a function of PAC dose. 
The turbidity decreased, in accordance with the theory, will be proportional to the decrease in TSS as shown in Figure 3. The suspended solid of a solution will change the color and enhance the turbidity of a solution, while decreasing the number of suspended solids will increase the brightness of the solution. Trends in dosage variation in turbidity are also similar to TSS, although dosing of $500 \mathrm{ppm}$ results in the highest decrease, but not significantly different from the doses of $300 \mathrm{ppm}$ and $400 \mathrm{ppm}$.

Figure 4 presents the effect of PAC dose on COD reduction from waste water. The decrease in COD only 8 - 28\%, although it proved that the coagulation flocculation process can decrease the COD. The low COD drop may be due to the addition of a $\mathrm{NaOH}$ solution at the beginning of the process, thus adding the inorganic substances that must be oxidized. Figure 4 also shows that the trend of COD degradation increases with peak at doses of $300 \mathrm{ppm}$ and $400 \mathrm{ppm}$, but at a dose of $500 \mathrm{ppm}$ COD decreases significantly. The decrease occurred due to the addition of doses up to $500 \mathrm{ppm}$ will damage the destabilization of ions or organic substances so that the degradation of COD after coagulationflocculation decreased.

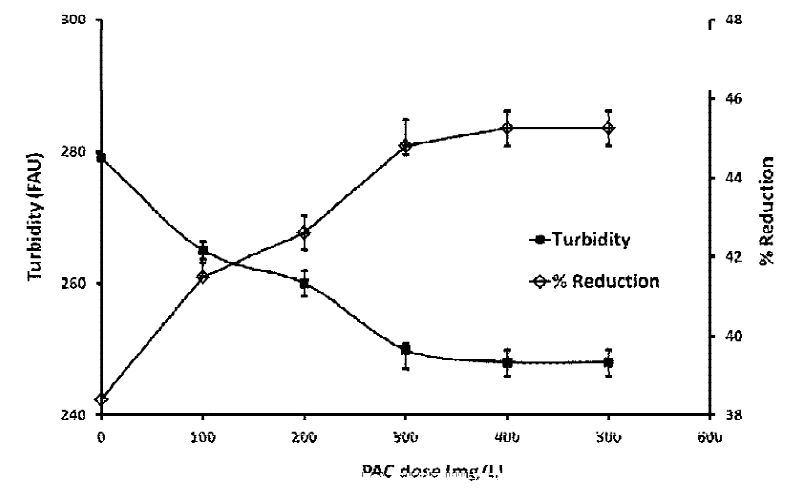

Fig. 3. Turbidity and turbidity reduction of wastewater after coagulation-flocculation process as a function of PAC dose.

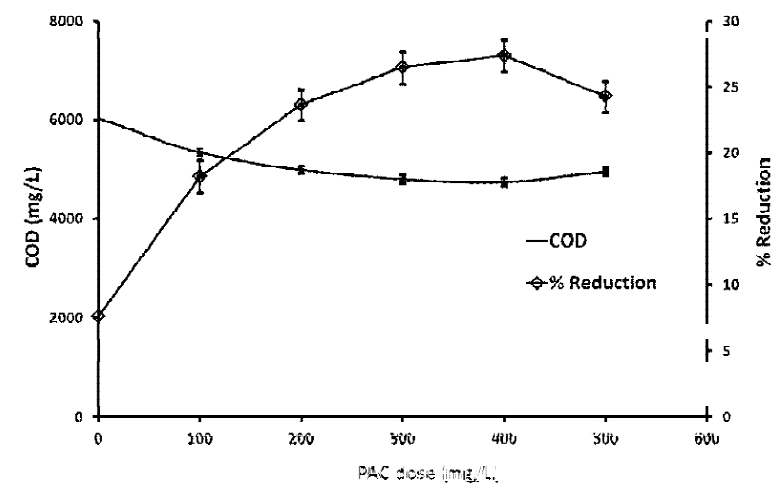

Fig. 4. COD and COD reduction of wastewater after coagulation-flocculation process as a function of PAC dose.

Figure 5 shows the effect of PAC dosage on the effectiveness of the coagulation-flocculation process on
TDS parameter. TDS tend to increase with increasing the PAV dose due to the addition of $\mathrm{NaOH}$ to adjust the $p \mathrm{H}$ of wastewater to 7. The increase of TDS can also occur due to solids of medium size (colloidal transition) dissolved into the wastewater solution. Although after the precipitation process was filtered with qualitative filter paper, the soluble solids will still pass from the filter paper due to its size smaller than 0.45 microns. The TDS value for each coagulant dose variation from $0 \mathrm{ppm}$ to $500 \mathrm{ppm}$ showed no significant difference, so that the optimum dose selection in this process could not be determined from the TDS parameter.

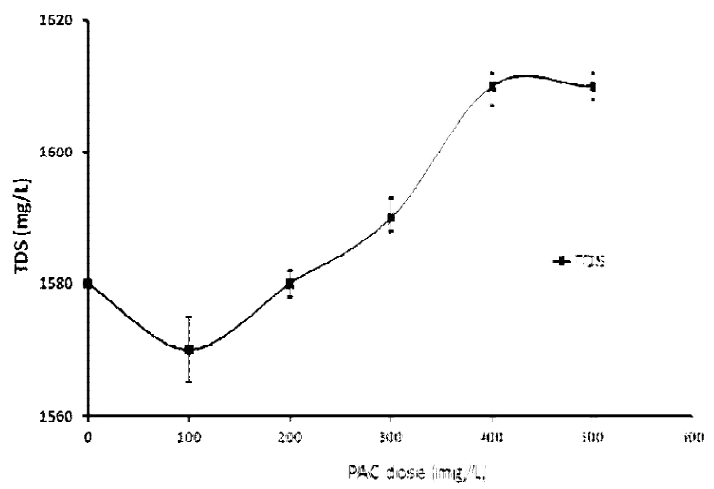

Fig. 5. TDS of wastewater after coagulation-flocculation process as a function of PAC dose.

Based on coagulation-flocculation experiment, the result of the experiment using PAC dose of $300 \mathrm{ppm}$ will be used as a feed on the ultrafiltration process. The ultrafiltration experiments were conducted through dead end process. The membrane flux increased with increasing TMP due to the increase of the driving force for the liquid to pass through the membrane pores as presented in Figure 6.

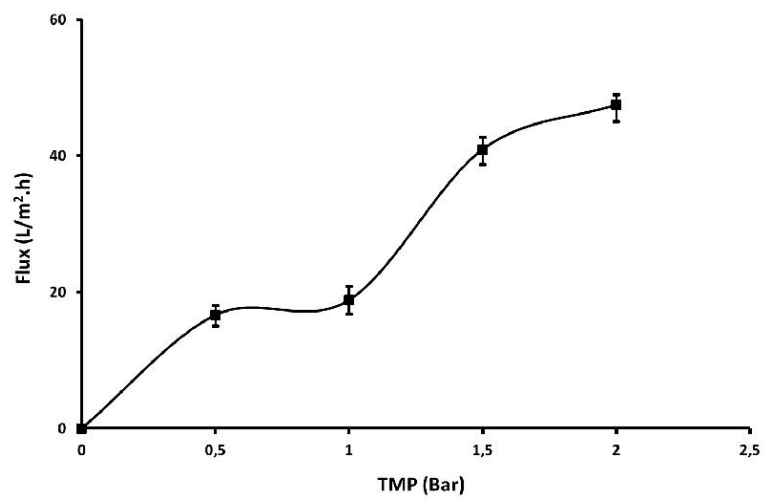

Fig. 6. Membrane flux in ultrafiltration process as a function of TMP.

The TSS of produced water from the ultrafiltration process is demonstrated in Figure 7. The TSS decreased drastically in the ultrafiltration process with removal efficiency more than 98\%. This means that the ultrafiltration membrane is able to withstand the suspended solids not to penetrate the membrane pores. 
The TSS of produced water relatively constant with the TMP and meets the National Environmental Quality standard, which is $200 \mathrm{mg} / \mathrm{L}$, while the lowest TSS of produced water is $1 \mathrm{mg} / \mathrm{L}$. The similar phenomena also occurred for Turbidity as shown in Figure 8, where the turbidity decreased drastically in the ultrafiltration process with removal efficiency more than 95\%. The turbidity of produced water also meets the National Environmental Quality standard, which is 25 FAU, while the lowest turbidity of produced water is 9 FAU. Figure 9 shows the brightness of initial tofu wastewater, wastewater after coagulation-flocculation process and produced water after ultrafiltration process. It can be seen that the produced water from ultrafiltration process is much clearer than initial tofu wastewater.

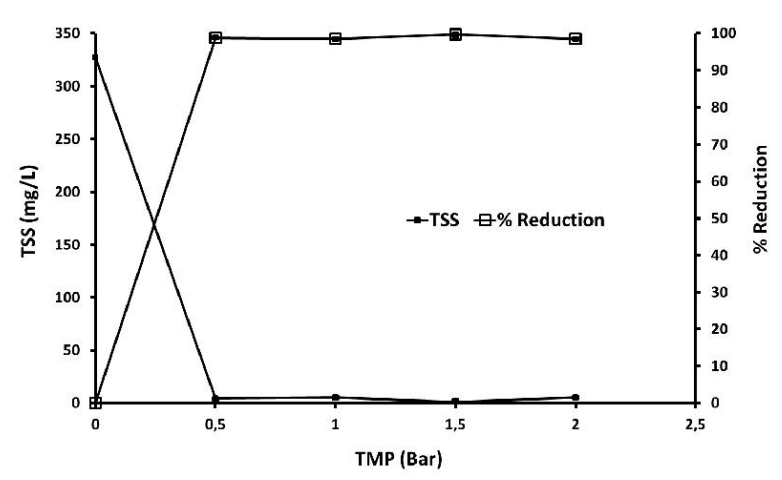

Fig. 7. TSS and TSS reduction of wastewater after ultrafiltration process as a function of TMP.

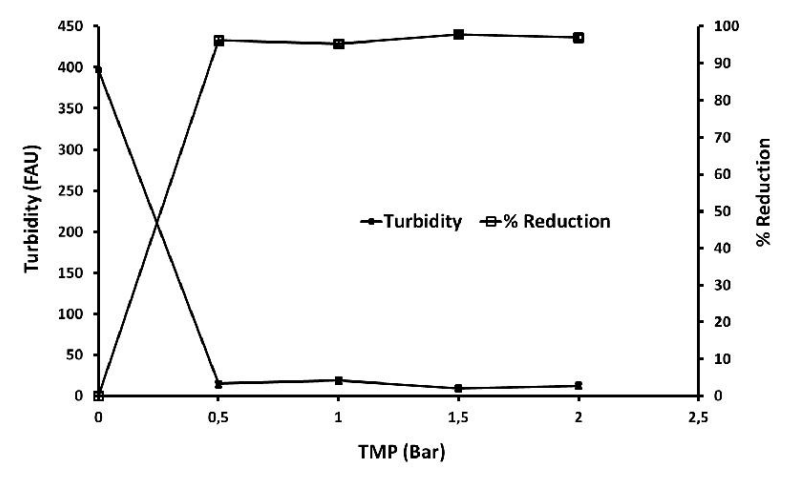

Fig. 8. Turbidity and turbidity reduction of wastewater after ultrafiltration process as a function of TMP.

The COD of produced water after ultrafiltration process is demonstrated in Figure 10. The COD decreased with TMP until 1.5 Bar and then increased at TMP 2 Bar. This means that the ultrafiltration membrane is able to retain the chemical substances not to pass through the membrane pores until the TMP is 1.5 Bar, but when the TMP is increased, more chemical substances can penetrate the membrane pores due to the higher driving force. The COD of produced water do not meet the National Environmental Quality standard, which is $275 \mathrm{mg} / \mathrm{L}$, while the lowest COD of produced water was $1460 \mathrm{mg} / \mathrm{L}$. However, the BOD of produced water is very low, as shown in Table 2, indicating that the organic materials from the wastewater can be well removed in the ultrafiltration process. The high of COD value is due to $\mathrm{Na}^{+}$ion in the produced water that cannot be rejected by the membrane pores in the ultrafiltration process. The ion $\mathrm{Na}^{+}$was added in the wastewater for $p \mathrm{H}$ adjustment before pretreatment coagulation-flocculation process in the form of $2 \mathrm{M} \mathrm{NaOH}$ solution. The similar phenomenon also appears for TDS as shown in Figure 11, where TDS decreased with TMP until 1.5 Bar and then increased at TMP 2 Bar. However, TDS of produced water still meet the National Environmental Quality standard, which is $2000 \mathrm{mg} / \mathrm{L}$, while the lowest TDS of produced water is $630 \mathrm{mg} / \mathrm{L}$.

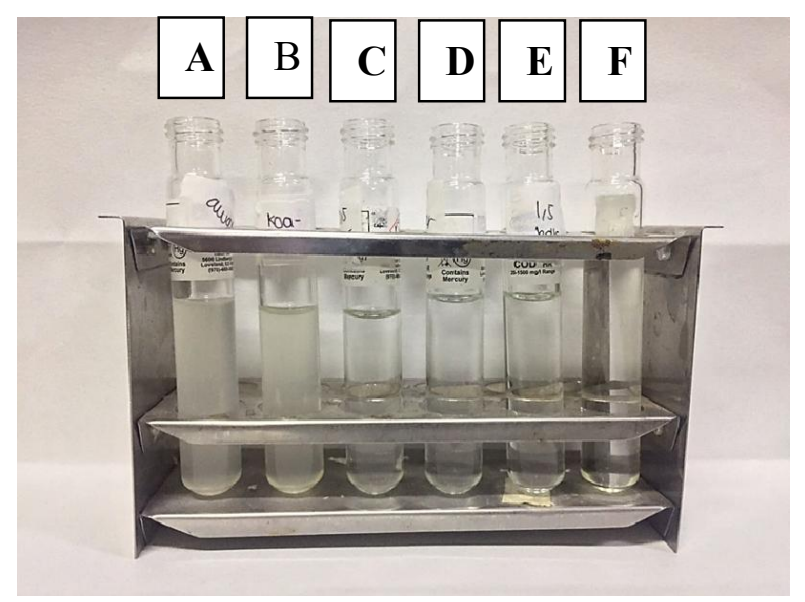

Fig. 9. The brightness of wastewater, A: initial wastewater; B: wastewater after coagulation-flocculation process; C, D, E and F: produced water of ultrafiltration processes at TMP of 0.5 , 1.0, 1.5 and 2.0 Bar, respectively.

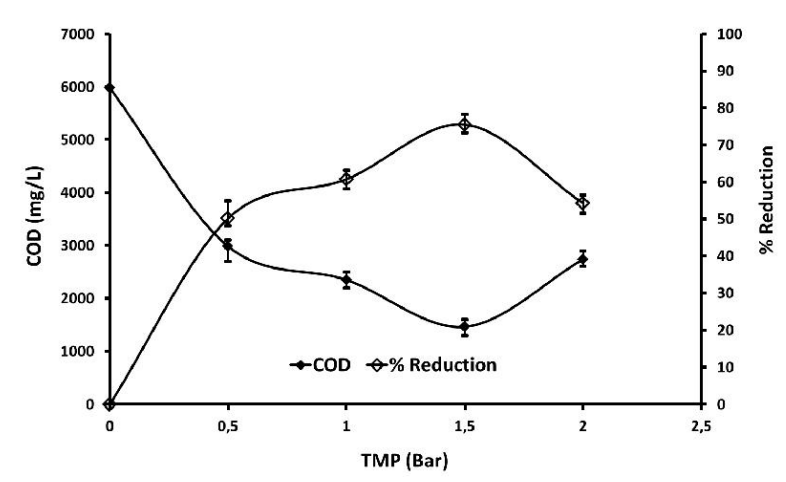

Fig. 10. COD and COD reduction of wastewater after ultrafiltration process as a function of TMP.

The parameters resulted from ultrafiltration process for TMP of 1.5 Bar together with the National Environmental Quality Standard is tabulated in Table 2. It can be noticed that all parameters except COD meet the requirements of the National Environmental Quality Standard. The high of COD was due to $\mathrm{Na}^{+}$ion that cannot be separated using ultrafiltration membrane as the $\mathrm{Na}^{+}$ion diameter is still much lower than the ultrafiltration membrane pore diameter. The $\mathrm{Na}^{+}$ion can be further separated using reverse osmosis membrane. 


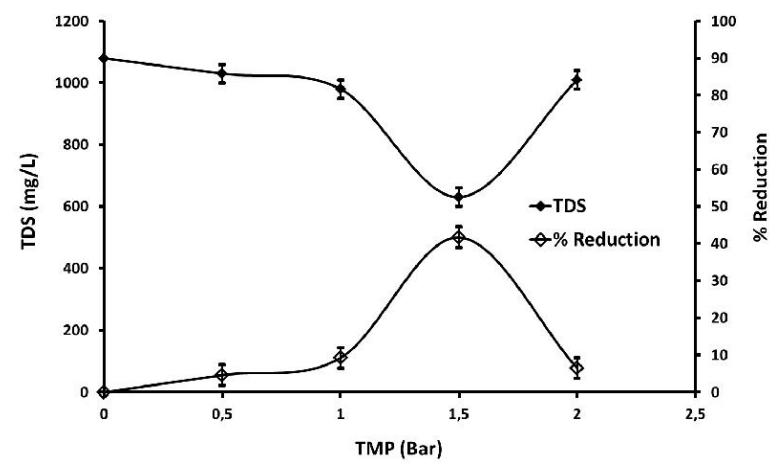

Fig. 11. TDS and TDS reduction of wastewater after ultrafiltration process as a function of TMP.

Table 2. The characteristics of the produced water by the ultrafiltration process.

\begin{tabular}{|l|c|c|}
\hline $\begin{array}{c}\text { Observed } \\
\text { Parameters }\end{array}$ & $\begin{array}{c}\text { After } \\
\text { Ultrafiltration }\end{array}$ & $\begin{array}{c}\text { Government } \\
\text { Regulation [6] }\end{array}$ \\
\hline TSS $(\mathrm{mg} / \mathrm{L})$ & 5 & 100 \\
\hline Turbidity $(\mathrm{FAU})$ & 10 & 25 \\
\hline TDS $(\mathrm{mg} / \mathrm{L})$ & 630 & 2000 \\
\hline COD $(\mathrm{mg} / \mathrm{L})$ & 1464 & 275 \\
\hline BOD $(\mathrm{mg} / \mathrm{L})$ & 9.6 & 150 \\
\hline
\end{tabular}

\section{Conclusions}

The study has been conducted to see the effects of combination of coagulation-flocculation and ultrafiltration processes in tofu wastewater treatment. To measure the success of the combination of coagulationflocculation and ultrafiltration processes, the parameters such as TSS, turbidity, COD, BOD and TDS are used as tools. The produced water at the end of the treatment, which is in the ultrafiltration process, met the requirements of the National Environmental Quality Standard except for COD. The high of COD value was due to ion $\mathrm{Na}^{+}$in the produced water that cannot be retained by the membrane pores in the ultrafiltration process.

The authors are appreciative to the funding from PITTA Project provided by the Directorate of Research and Public Service Universitas Indonesia through Contract No . 2542/UN2.R3.1/HKP.05.00/2018.

\section{References}

1. Central Bureau of Statistics of Republic of Indonesia, The average consumption per capita per week of some important foods (2015).

2. Center for Agricultural Data and Information 4, 1624 (2013).

3. Ministry of Industry, http://kemenperin.go.id/ statistik/ibs indikator.php?indikator=1 (2016).

4. M. Faisal, A. Gani, F. Mulana, H. Daimon, Asian J. Chem. 28, 501 (2016).
5. F. Belén, J. Sánchez, E. Hernández, J.M. Auleda, M. Raventós. J. Food. Eng. 110, 364-373 (2012).

6. Ministerial Regulation of the Ministry of Environment No. 5 (2011).

7. S. Anggarini, N. Hidayat, N. M. S. Sunyoto, and P. S. Wulandari. Agr. Agri. Sci. Proce. 3, 95-101 (2015).

8. Z. Xue, C. Wang, J. Cao, J. Luo, Q. Feng, F. Fang, C. Li, Q. Zhang. Biochem. Eng. J. 132, 217-224 (2018).

9. H. Zhu, T. Suzuki, A. A. Tsygankov, Y. Asada, J. Miyake. Int. J. H. En. 24, 305-310 (1999).

10. S.-K. Wang, X. Wang, J. Miao, and Y.-T. Tian, Biores. tech. 253, 79-84 (2018).

11. F. Febrianti, K. Syamsu, M. Rahayuningsih. Int. J. of. Tech. 8(5), 898-908 (2017).

12. V. Doraisammy, G. S. Lai, S. Kartohardjono, W. J. Lau, K. C. Chong, S. O. Lai, H. Hasbullah, A.F. Ismail, Can. J. Chem. Eng. 96, 1612-1619 (2018).

13. A. Arinaldi, F. Ferdian, and I. N. Widiasa. J. Tek. Kim. Ind. 8-13 (2013). 